\title{
Water covers for tailings and waste rock — designing for perpetuity
}

\author{
D.M. Brett GHD Pty Ltd, Australia
}

\begin{abstract}
Water covers are recognised as a preferred method of controlling oxidation of sulphides in tailings and waste rock, in climates where the availability of water is adequate to maintain continuous saturation. However, there is a resistance to this method for long-term, low maintenance closure of these storage facilities due to the perceived risks associated with water storage dams. Dams are closely regulated by government in most jurisdictions and require management systems appropriate to the hazard rating of the structure. This is determined in Australia using guidelines issued by the Australian National Committee on Large Dams (ANCOLD) and others, relating to the consequences of failure. Most mine storages would fit into the ANCOLD high hazard rating due to the environmental impact of their failure. The hazard rating imposes recommendations for design parameters, construction details and ongoing operational management. However, these recommendations have generally been developed for operating water storage dams and require a level of management that becomes unrealistic for a closed mine storage. The solution is to develop design and construction practices for mine waste storages that reduce the risk of failure to acceptably low levels that allow reduction in the scope of long-term management.
\end{abstract}

This paper describes how risk assessment methods can be used to develop the design of mine waste storages that can support water covers for long-term performance.

\section{Introduction}

Often the prevention or control of acid rock drainage (ARD) from mine wastes is one of the most difficult environmental issues to manage during the operation of a mine and very likely is the most difficult aspect to manage in mine closure and abandonment. Modern mining practice seeks to develop a sustainable industry. Consequently the basic requirement of mine waste disposal is to provide "safe, stable and economic storage... presenting negligible public health and safety risks and acceptably low social and environmental impacts during operation and post-closure" (DITR, 2007). ARD can be controlled during operations by various means depending on the lag time of acid generation following exposure of sulphides in tailings or waste rock to oxygen. However, the problem becomes more difficult following closure when the timeframes for exposure become extended, particularly if this is required to be in perpetuity and regulators are asked to approve mine closure plans and ultimately accept relinquishment of mine leases.

Current practice is to encapsulate reactive wastes in inert soil or rock covers in an attempt to limit oxygen ingress, or at least to limit water infiltration leading to seepage of acidic leachate, if prevention of oxidation is not feasible. Various systems have been developed in Australia where much of the mining provinces have arid climates. This approach is unlikely to be $100 \%$ effective in preventing seepage and furthermore, usually relies on relatively thin coverings that are likely to be susceptible to damage and failure over very long periods of time.

In suitable climates however, saturation of wastes can be feasible. If this leads to a permanent water cover then the waste storage will be likely to be perceived as a "dam", falling under the close regulation relevant to water storage dams. This will include prescribed requirements for design parameters, construction details and ongoing operational management, arguably to a level of management that becomes unrealistic for a closed mine waste storage. But the question should be asked, "Is the risk of failure of a saturated, water-covered mine waste storages any different to a conventional covered storage.

\section{When is a dam not a dam?}

Clearly a water covered tailings or waste rock storage is a dam by definition, but other closure systems can also become dams under extreme climatic conditions. Even dry cover tailings storages can be considered to 
be dams as, for example, in Tasmania, where the Tasmanian Water Management Act 1999 defines "dam" as a "permanent or temporary barrier or structure that stores water or other liquids, silt, debris, mine tailings or other liquid-borne material or holds back or impedes the flow of water or other material...." (Brett, 2008). Thus, tailings storages with both water cover and soil cover fall under the Tasmanian Water Management (Safety of Dams) Regulations 2003, requiring them to meet amongst others, the requirements of various ANCOLD guidelines. In other jurisdictions this could well also be the case through common law requirements to meet common best practice (Pisaniello and McKay, 2006).

This is considered to be appropriate, as the ANCOLD (2003) "Guidelines on Dam Safety Management 2003 " is quite relevant to a waste storage, whether or not it has a water-cover. The objective of the guideline is to "protect life, property and the environment." The elements of a dam safety program could apply equally to a waste storage, landfill or many other types of engineering structure. The dam safety program revolves around the key issues of planning, design, construction, operation and maintenance, surveillance, safety reviews, risk assessments, reporting, training, emergency preparedness, deficiency detection and remedial action - all directly relevant to any type of mine waste storage facility. Brett (2008) described an example of a covered, low permeability tailings storage in a wet climate where the tailings could remain saturated despite the cover. This example could result in similar risks of embankment instability for a water-covered storage.

In dry climates, another example would be the effect of a major flood on a dry covered storage, where the available storm storage capacity can be exceeded and the storage perimeter overtopped. In this case the dry covered storage would become a dam even though only temporarily.

\section{Geographical spread of water cover potential}

In Australia, water covers are common and considered leading practice in Tasmania where the climate is relatively wet with low evaporation. Similar conditions occur in northern parts of North America, Europe and Asia. Water covers could also be feasible in tropical areas where high evaporation is balanced by high and regular rainfall. In more arid areas, water covers could still be feasible if modified to allow saturation of wastes below an evaporation-reducing cover system.

\section{$4 \quad$ Risk of dam failure and the relationship to design life}

Review of the statistical rate of failure of embankment dams (for water storage) (Foster et al., 1998) suggests an average annual risk of failure of around $8 \times 10^{-5}$. This figure would include a wide variety of causes of failure, with piping accounting for approximately $50 \%$ and earthquake only $1.5 \%$. Failure is historically approximately twice as likely during the first five years. The failure rate of tailings dams during operation is probably higher.

Event trees can be used to determine the risk of failure in individual cases by exploring potential failure modes and assigning probabilities to the various branches of the tree (Fell et al., 2000). This can be used to determine the quantitative risk of particular failure modes.

For closure of mine waste facilities the design life needs to be a very long time, often described as in perpetuity. In practice it is unrealistic to interpret this as forever. In Sweden, which has been subject to ice ages at various times, it is considered not possible to design structures of any type to be stable under ice age conditions. Accordingly a design life of 10,000 years is often described. In parts of Australia it is likely that even longer times might be reasonable.

If the annual risk of failure is considered in context with the expected design life, an annual risk of failure of $2 \times 10^{-5}$ might be quite reasonable for an engineered structure intended to last for 100 years where the overall risk of failure during the design life approaches an acceptable value close to $2 \times 10^{-3}$ but is unacceptable when extended to even 10,000 years when failure becomes nearly inevitable.

Consequently, for mine waste storages the design for closure must be based on reducing the risk of failure to very low values, of at most $10^{-6} /$ storage/year or lower. To achieve this, the designers need to be looking at natural or man-made analogues and mimicking systems that have demonstrated stability over geological time scales. 


\section{$5 \quad$ Analogues of stable earth structures}

The Geological Survey of Sweden (Bjelkevik, 2005) has investigated several natural glacial lakes formed by soil deposits and compared them to constructed dams. These included four examples with ages up to 8500 years, comprising sand, silt and clay moraine materials. It was found that the hydraulic gradients within the structures ranged from $2-4 \%$. Two of the examples have subsequently been accidentally destroyed by human intervention. Similar lakes can be found in Tasmania but no data is available other than verbal advice that "outlet channels feature large boulders" (Anon, pers. comm., 2009).

Various man-made earth structures have also been studied (Bjelkevik, 2005), with ancient mounds and burial sites up to $50 \mathrm{~m}$ high being still stable after over 5000 years.

These analogues suggest that it is possible to design structures for the extreme long life required by mine waste storages, provided the correct design parameters can be determined.

\section{$6 \quad$ Failure modes of mine waste storages and design parameters}

The potential failure modes of a mine waste storage are:

- Flood overtopping: This failure mode can apply equally to water or soil covered tailings storages, if surface drainage is not adequately designed to provide drainage paths suitable to safely divert the maximum design flood deemed appropriate. If designing for closure it is suggested that the design flood needs to be conservatively sized for a probable maximum flood (PMF) in either case. The PMF is the estimated flood resulting from a probable maximum precipitation (PMP), a theoretical rainfall based on the maximum water holding capacity of the atmosphere at a specific location. In Australia, the PMP varies from around $0.5 \mathrm{~m}$ in 6 hours in lower latitudes to in excess of one metre over four hours in tropical zones. The PMP is not based on historic rainfall data but can be assigned a statistical risk of between $10^{-6}$ and $10^{-7} /$ year, depending on the catchment area. The author considers this to be a reasonable design basis for flood assessment and if a wide cutting in sound rock can be provided then the risk should be satisfactorily addressed. Alternatively, a large freeboard to allow retention of floods and limiting flows could achieve the same result. Siting storage to limit any additional catchment area can also assist. The impact of future settlement, including potential liquefaction under earthquake loading, on the freeboard needs to be assessed by available methods such as the simplified method (Makdisi and Seed, 1978) or more sophisticated finite element analyses. In addition, vegetation growth, erosion, siltation and other degradation of the drainage system needs to be considered.

- Embankment stability: Embankment stability is determined by the strength of construction materials, the geometry of the embankment slopes, the location of the phreatic surface (water table within the structure) and the external loads. Design usually includes stability analysis using slip circle methods with target factors of safety. In normal design procedures the designers are attempting to minimise the size and hence cost of a structure to just meet the required factors of safety. However, in design for closure it is suggested that other factors need to be considered. This will most likely see much higher factors of safety for mine waste storages than normal for engineering structures.

The material strengths and geometry can often be influenced by the availability of mine wastes themselves to create much more robust structures. This could see, for example, strategic placement of waste rock as part of tailings storage design to create buttressing to a tailings storage, such that the stability becomes extremely low risk. Another possibility would be the use of co-disposal techniques to result in much enhanced material strength and drainage parameters.

The location of the phreatic surface can be controlled by external capping, internal drainage and embankment detailing. For example, even a partial cover can significantly lower the phreatic surface, reduce seepage and increase stability, as demonstrated in the mushy closure option at Henty Mine in Tasmania (Brett and French, 2008).

- Tailings liquefaction: A major reduction in strength of fine-grained silty soils can occur during earthquakes. To design for perpetuity it would be necessary to allow for a maximum credible earthquake (MCE). It is possible to determine a site-specific earthquake by review of local faults and 
geological conditions but ANCOLD (1998) have suggested a generic ground acceleration relationship for the east coast of Australia as shown in Figure 1. This shows that the recommended ground acceleration for an average annual exceedence probability of $5 \times 10^{-5}$ is approaching $0.5 \mathrm{~g}$.

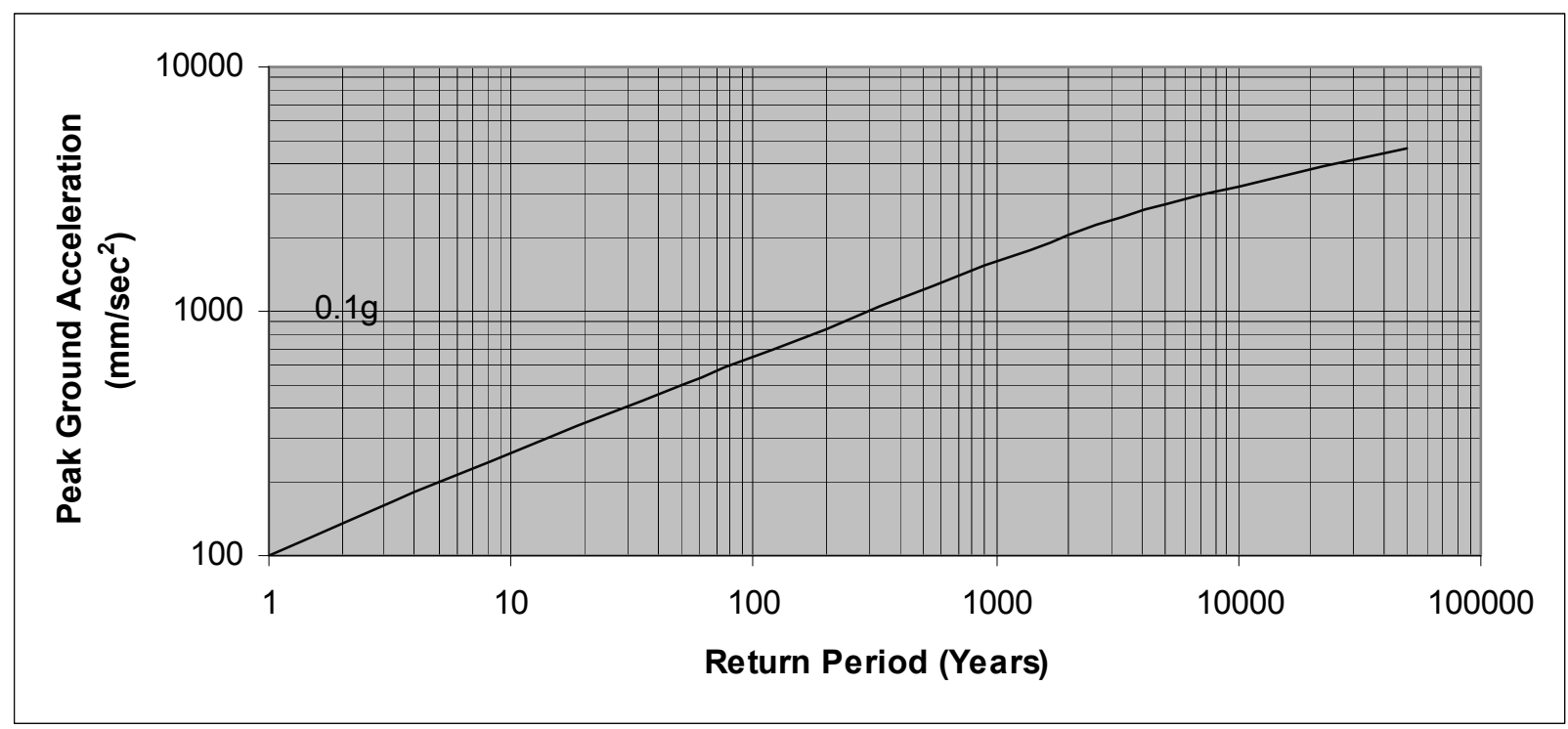

\section{Figure 1 ANCOLD earthquake design recommendation for the east coast of Australia}

This level of acceleration, particularly with magnification by thick deposits of loose tailings, is likely to cause liquefaction of tailings unless they have become relatively dense. This will lead to a very significant reduction in strength immediately post-earthquake and potentially large deformation and settlement of the storage structure. The magnitude of potential settlements needs to be determined to ensure that freeboard against overtopping of the storage structure is not compromised. Settlement could also be caused through normal consolidation of tailings over time together with potential chemical effects leading to an apparent increase of strength of tailings with time (Eurenius, 1990).

- Internal erosion: The risk of internal erosion and subsequent piping failure is reduced in conventional water storage dams using properly designed filters. However, there is doubt about the long-term performance of filters in mine waste storages due to potential blocking by chemical precipitation over the expected long-term life.

Another method for risk reduction is the reduction of seepage forces by ensuring a low phreatic surface. Benckert and Eurenius (2001) suggest that the risk of internal erosion is low if the hydraulic gradient of the phreatic surface is less than half the angle of friction of the downstream zone of an embankment. This would typically allow an angle of $10-15^{\circ}$. This range is still higher than that measured in the natural analogues previously discussed but does give a direction for safe design.

The other factor of importance regarding potential piping failure of a tailings storage facility is the potential for maintaining a piping flow with tailings, particularly if good spigotting practices or the grind of the tails results in a broad sandy zone near the embankment.

- Surface erosion: The natural process of erosion will ultimately reduce any landform but the ancient structure analogues previously described confirm that slopes can remain stable for the timeframes of thousands of years. Stable slopes need to consider the materials exposed and the potential velocity of water flow or other erosive forces. The rainfall events and flows that need to be considered once again need to be extreme. The erosion potential needs to apply to general batter slopes but also drains and areas where flow concentration will occur. Using extreme flows will result in the need for conservative slopes unless non-sulphide waste rock is able to be used to advantage in establishing armoured slopes. However, too often the short-term costs of waste rock carting are the focus of the miners with the result that safe closure opportunities are missed. 
Landform design needs to look for natural analogues for direction to stable slopes and shapes. Often benches are proposed in mine landforms with the intention of reducing overland flow paths. However, benches do not occur in nature unless due to some base geological feature and will inevitably fail through siltation, vegetation blockage or localised erosion. Consequently, it is considered that they should not be part of landform design for closure.

\section{Conceptual mine waste facility model for closure}

While every mine waste storage facility will be unique, a generic model with features discussed in this paper to reduce the risk of failure could follow Figure 2 .

This features the following:

- A conventional dam for the operational phase preferably with a water retaining structure featuring a clay internal zone and upstream and downstream zones, preferably with a properly designed filter.

- A final downstream face designed with slopes that are erosion resistant considering the nature of the exposed material and potential extreme rainfall. Note that soil slopes would be very flat but use of rock armouring could steepen. A parabolic convex profile might be appropriate with steeper slopes on upper area where the catchment is reduced so flow and velocity would be less. Use of nonsulphidic waste rock as a conservative buttress could be appropriate.

- Potentially co-disposed sulphidic waste rock on the upstream side. This would be appropriate for preventing oxidation and also to strengthen the embankment, increase steady state stability and reduce the potential for liquefaction and settlement during earthquake loading.

- A permanent water level with sufficient catchment/rainfall reliability to prevent drying to expose tailings.

- An engineered soil cover over exposed beaches, designed to remain saturated during drought periods and to stop oxygen ingress to unsaturated sulphidic waste. Alternatively non-sulphide wastes could be placed in zones that would become unsaturated.

- A spillway capable of passing the PMF with remaining freeboard in excess of the worst-case projection of crest settlement due to consolidation or earthquake induced deformation.

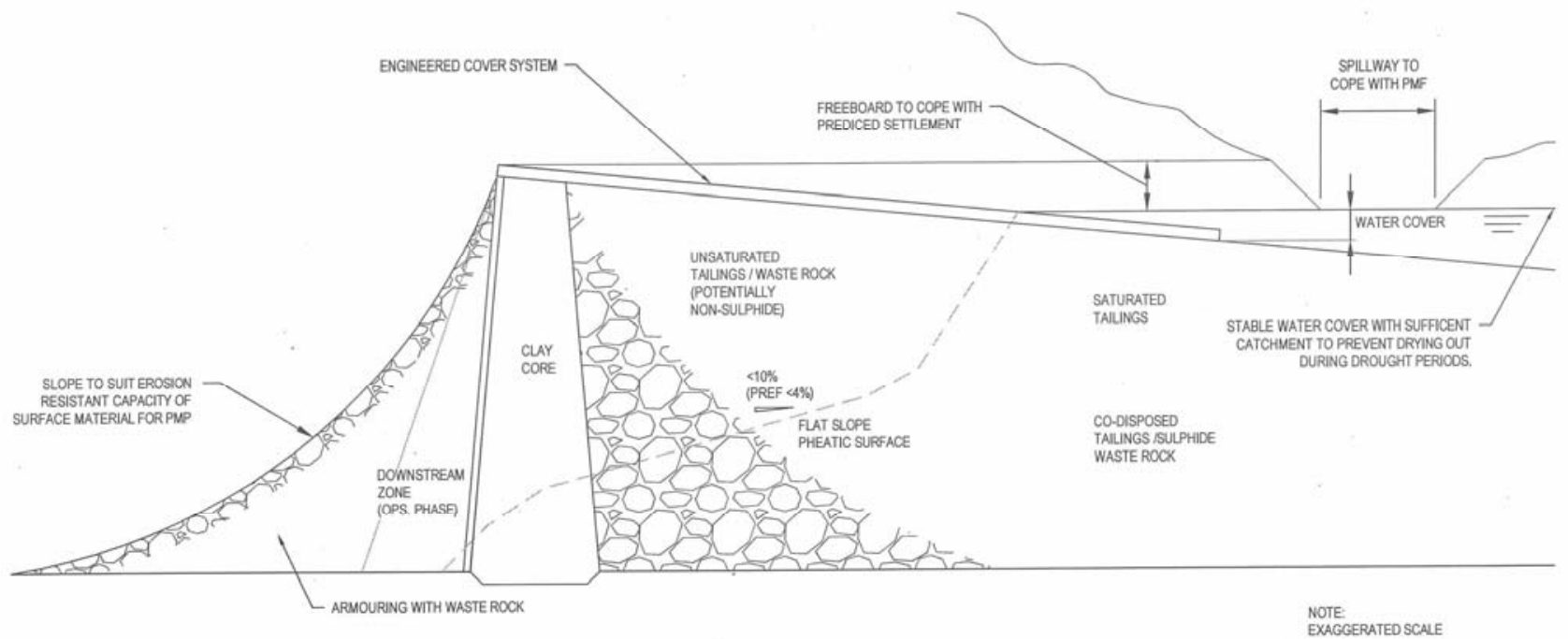

Figure 2 Conceptual mine waste storage facility model for closure - exaggerated vertical scale

Obviously this is a hypothetical model and has room for discussion/criticism but it is considered not to be too far from current good practice to suggest that with a bit more attention to detail it should be possible to design mine waste storages to allow closure with confidence that the structures can perform with limited 
maintenance in perpetuity. Some examples of performance of water covered waste storages are discussed by Brett et al. (2009).

\section{Risk assessment}

Risk assessment can be carried out on two levels. The first comprises a qualitative high level overview of potential risks posed to the community, workforce and the environment. The second is a quantitative risk assessment of dam failure modes. In addition, the potential impact of a flow slide of tailings in the event of a dam breach has been assessed for information.

Qualitative risk assessment involves identifying risks and qualifying their likelihood and consequence to allow ranking using a risk analysis matrix such as that shown in Table 1.

Table 1 HB 203:2006 Table 4(C) - Qualitative risk analysis matrix: level of risk (SA/SNZ, 2006)

\begin{tabular}{lccccc}
\hline & \multicolumn{5}{c}{ Consequence } \\
\cline { 2 - 6 } Likelihood & Catastrophic & Major & Moderate & Minor & Insignificant \\
\hline Almost certain & E & E & E & H & H \\
Likely & E & E & H & H & M \\
Possible & E & E & H & M & L \\
Unlikely & E & H & M & L & L \\
Rare & H & H & M & L & L \\
\hline
\end{tabular}

Note: E, H, M, L denote Extreme, High, Moderate and Low respectively

The second method is quantitative risk assessment where failure modes are identified and event trees built up to describe the various conditions that need to be met for the failure to occur. An example is presented in Figure 3.

This shows an event tree for failure of a dam by overtopping during a flood with 1:100 annual exceedence probability (AEP). For dam overtopping in this case - firstly the flood occurs, then the diversion drain needs to be blocked or partially blocked, the spillway needs to be blocked or partially blocked, the dam has to overtop by a sufficient flow and for sufficient time to cause erosion that ultimately leads to failure. Each of the conditions is assigned a probability, determined by calculation or assessment. The probabilities of the conditions that lead to failure are multiplied to determine the total risk. The risks for each branch of the tree that leads to failure are added to get the overall risk. In this case the assessment was that the risk of the dam failing due to overtopping in a 1:100 AEP flood was $9 \times 10^{-9}$.

By repeating this sort of assessment for various potential failure modes it is possible to build up a risk profile for a structure, estimate the overall quantitative risk of failure and to highlight the critical issues that need to be addressed by design. 


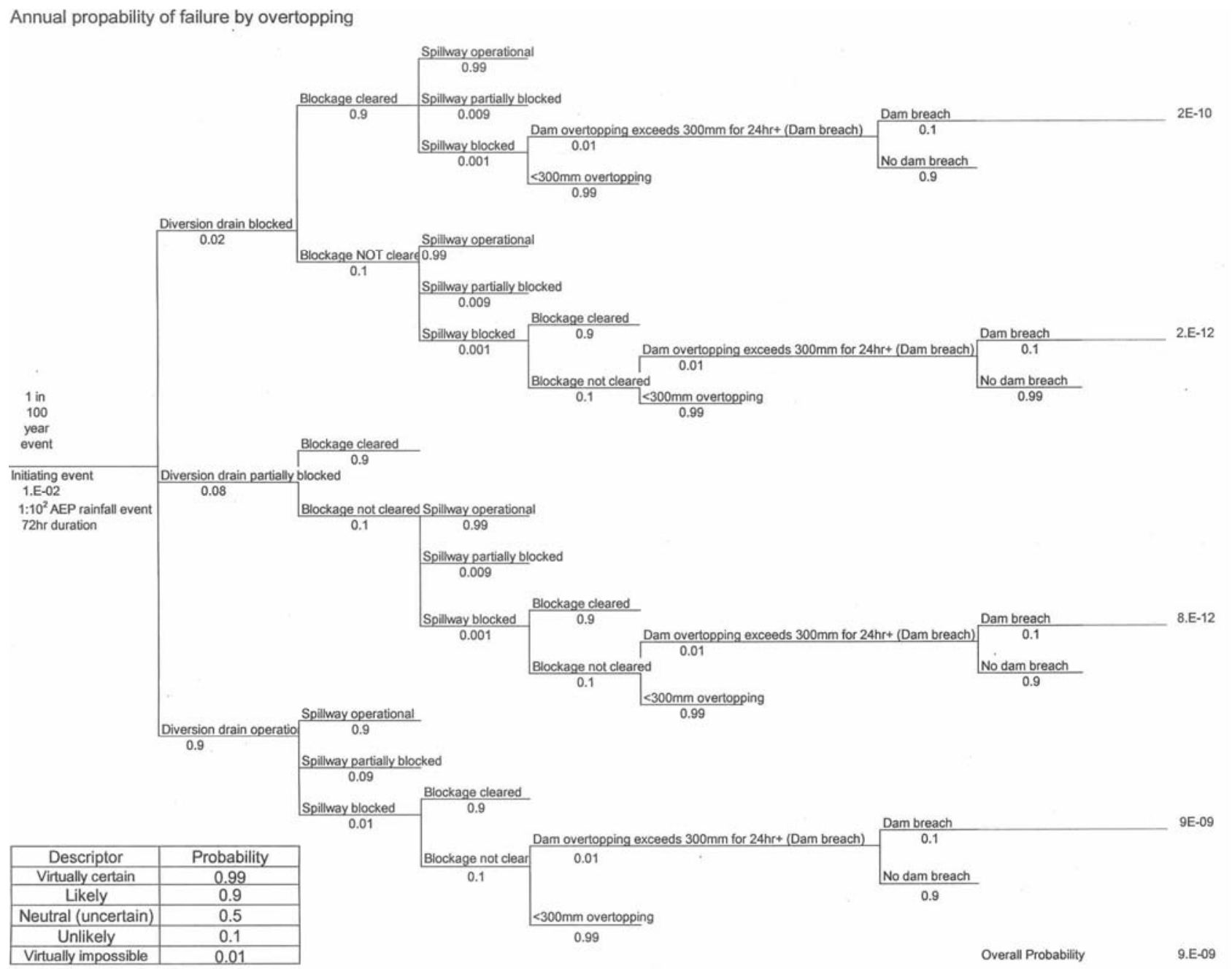

Figure 3 Example of an event tree

\section{Conclusion}

It is concluded that saturated mine waste storages with water cover are a viable and, from a technical viewpoint, preferable option for safe disposal of sulphidic materials prone to ARD generation, when climatic conditions allow saturation levels to be maintained. With appropriate design these structures can have a very low risk of failure, commensurate with the expected extremely long design life and potentially having lower overall risk to the environment and community to more conventional, soil covered disposal systems.

Modern engineering risk assessment techniques can be used to determine quantitative risk values and to highlight potential failure modes. This can allow designers to design out the inherent risks. In many cases, the design may highlight the need for better planning of mine waste disposal to make effective use of materials available on a site. In particular this could include the use of non-sulphide waste rock for conservative water retaining embankment construction.

With appropriate design features it is considered that regulators can treat approvals, closure and mine lease relinquishment of sites with water covers in a similar manner to conventional soil covered waste storages and there should be no need for avoidance of water covered structures based on perceived high risks of failure. 


\section{References}

Australian National Committee on Large Dams (ANCOLD) (1998) Guidelines for Design of Dams for Earthquake, $90 \mathrm{p}$.

Australian National Committee on Large Dams (ANCOLD) (2003) Guidelines on Dam Safety Management, 52 p.

Benckert, A. and Eurenius, J. (2001) Tailings Dam Constructions, Seminar on Safe Tailings Dam Constructions, Gallivare, Sweden, Swedish Mining Association, Natur Vards Verket, European Commission, pp. 30-36.

Bjelkevik, A. (2005) Water Cover Closure for Tailings Dams - State of the Art Report, Luleå University of Technology, Division of Geotechnology, Sweden, 103 p.

Brett, D.M. (2008) When Is A Dam Not A Dam? Annual Conference on Dams, ANCOLD, Gold Coast, Queensland.

Brett, D. and French, D. (2008) Mushy Closure of Pond-B, Barrick Henty Gold Mine, 6th Australian Workshop on Acid and Metalliferous Drainage (AMD), Burnie, Tasmania.

Brett, D.M., Koehnken, K. and Cordery, G. (2009) TSF Water Covers in Tasmania, Australia - Practice, Performance and Closure Issues, Securing the Future and 8th ICARD, Skellefteå, Sweden.

Department of Industry Tourism and Resources (DITR) (2007) Leading Practice Sustainable Development Program for the Mining Industry - Tailings Management, Australian Government.

Eurenius, J. (1990) Long-Term Studies and Design of Tailings Dams, International Symposium on Safety and Rehabilitation of Tailings Dams, Sydney, ICOLD.

Fell, R., Bowles, D., Anderson, L. and Bell, G. (2000) The Status of Methods for Estimating the Probability of Failure of Dams for Use in Quantitative Risk Assessment, International Commission on Large Dams, 20th Congress, Beijing, China.

Foster, M., Fell, R. and Spannagle, M (1998) Risk Assessment - Estimating The Probability of Failure of Embankment Dams by Piping, ANCOLD Conference on Dams, Sydney, Australia, Proceedings.

Makdisi, F. and Seed, H. (1978) A Simplified Procedure for Estimating Dam and Embankment Earthquake-induced Deformations, Journal of the Geotechnical Division, ASCE, Vol. 105, No. GT7, pp. 849-867.

Pisaniello, J.D. and McKay, J.M. (2006) The Need for Private Dam Safety Assurance: a follow-up 'model' policy from Tasmania', The Australian Journal of Emergency Management, Vol. 21, No. 2, pp. 45-51.

Standards Australia/Standards New Zealand (SA/SNZ) (2006) Handbook - Environmental Risk ManagementPrinciples and Process, third edition, HB 203:2006, Standards Australia, Sydney, and Standards New Zealand, Wellington, New Zealand, 98 p. 